\title{
Improve the Rapid Development of "High-tech" Industry Based on SWOT Model
}

\author{
SUN Jiazheng ${ }^{1, a}$, SUN Yibo ${ }^{1, b}$ \\ ${ }^{1}$ School of Economics and Management Beijing Information Science \& Technology University Beijing, China
}

\begin{abstract}
In order to promote the renewal and development of the capital city and avoid the "low-speed development trap" in the economy, the government proposed to use "high-tech" industries as the driving force to accelerate the construction of a "high-tech" industrial economic structure and increase investment in industrial innovation, so as to better guide and support overall and long-term development of economic and social. This article uses the SWOT analysis model, based on the actual development of Beijing's industry, deeply analyzes the advantages, disadvantages, opportunities and challenges of the city's development of "high-tech" industries, and proposes four aspects of countermeasure, such as improving fiscal and tax incentive policies, improving financing methods, optimizing industrial layout, promoting dual-chain integration. Beijing Municipal Government should speed up a reasonable "high-tech" industrial structure, give full play to the role of "high-tech" industries in "improving quality and efficiency" in Beijing's economic development, and then optimize and enhance the core functions of the capital.
\end{abstract}

\section{Introduction}

"High-tech" industry refers to the collection of such industrial forms as science and technology, product process, advanced inventions, material devices, organizational forms, and innovative applications with the characteristics of "advanced, precise and cutting-edge" [1]. In recent years, with the further development of the economy, the cost of factors such as land and manpower has continued to rise, and the traditional factor price advantage has gradually weakened. In order to avoid the above-mentioned disadvantages, China improve the economic structure, enhance economic efficiency, and propose to promote technological progress, innovation in management methods, and investment in intellectual property rights driven by "high-tech" industries. The purpose is to transform "Made in China" into "Created in China", increase industrial added value, increase corporate profits, and avoid the economy into a slump.

At the end of 2017, Beijing issued ten "high-tech" industry opinions to increase support for "high-tech" industries and promote high-quality economic development [2]. Subsequently, the municipal government put "scientific and technological innovation" in a prominent position, make every effort to promote the construction of a national scientific and technological innovation center, has completed the "three cities and one district" plan based on "four centers" urban development positioning, accelerate the construction of a "high-tech" industrial economic structure, promote coordinated development, give full play to the leading and supporting role of Zhongguancun Demonstration Zone, and build a world-class "high-tech" industrial economic structure. In this background, this paper deeply analyzes the advantages, disadvantages, opportunities and challenges of the city's development of "high-tech" industries, comprehensively control the development trend of "hightech" industries. In order to better play the role of "hightech" industries in promoting the economic development of the capital, this article puts forward relevant suggestions from four levels: fiscal and tax incentives, financing, industrial layout, and dual-chain integration, jointly promotes the integration of "high-tech" industries into the region as soon as possible, and provides strong momentum for the capital economic development [3].

Table1. BEIJING'S TOP TEN HIGH-TECH INDUSTRIES AND THEIR REGIONAL DISTRIBUTION

\begin{tabular}{|l|l|l|l|l|l|l|l|l|l|l|}
\hline \multicolumn{1}{|c|}{ City } & (1) & (2) & (3) & (4) & (5) & (6) & (7) & (8) & (9) & (10) \\
\hline Fangshan & & $\sqrt{ }$ & & $\sqrt{ }$ & & & $\sqrt{ }$ & & & \\
\hline $\begin{array}{l}\text { Mentougo } \\
\text { u }\end{array}$ & & & & $\sqrt{ }$ & & & & & & \\
\hline Yanqing & & & & & $\sqrt{ }$ & $\sqrt{ }$ & & & & \\
\hline Xicheng & & & & & & & & & $\sqrt{ }$ & \\
\hline Huairou & & & & & & & $\sqrt{ }$ & & & \\
\hline Changping & & $\sqrt{ }$ & & $\sqrt{ }$ & $\sqrt{ }$ & & & & & \\
\hline Fengtai & $\sqrt{ }$ & & & $\sqrt{ }$ & $\sqrt{ }$ & & $\sqrt{ }$ & & & \\
\hline $\begin{array}{l}\text { Shijingsha } \\
\mathrm{n}\end{array}$ & & & & & & & & & $\sqrt{ }$ & \\
\hline Haidian & $\sqrt{ }$ & & & & & & & $\sqrt{ }$ & $\sqrt{ }$ & $\sqrt{ }$ \\
\hline Chaoyang & $\sqrt{ }$ & & & & & & & & $\sqrt{ }$ & \\
\hline
\end{tabular}




\begin{tabular}{|l|l|l|l|l|l|l|l|l|l|l|}
\hline Tongzhou & & & & & & & & & $\sqrt{ }$ & $\sqrt{ }$ \\
\hline Shunyi & & & & & & $\sqrt{ }$ & & & & \\
\hline $\begin{array}{l}\text { Dongchen } \\
\text { g }\end{array}$ & & & & & & & & & $\sqrt{ }$ & \\
\hline Miyun & & & & & $\sqrt{ }$ & & & & & \\
\hline Daxing & $\sqrt{ }$ & $\sqrt{ }$ & & $\sqrt{ }$ & & $\sqrt{ }$ & & & & \\
\hline
\end{tabular}

a. (1) Next-generation information technology; (2) Medicine and health; (3) integrated circuit; (4)Intelligent equipment; (5)Energy saving and environmental protection; (6) new energy vehicles; (7) new material; (8)Artificial intelligence; (9)Software and information services; (10Technology Service Industry

\section{SWOT Analysis on the Development of "high-TECH" Industry in Beijing}

As the capital of China, Beijing has gathered abundant resources and laid a good foundation for the development of "high-tech" industries. However, Beijing also need to face up to the lack of development of "high-tech" industries in this city. Only by continuing to play to the advantages and make up for the shortcomings can Beijing better promote the development of the city. This paper uses the SWOT analysis model to analyze the advantages, disadvantages, opportunities and challenges of Beijing's development of "high-tech" industries.

\subsection{Advantage}

As the center of science and technology innovation center in China, Beijing has a high concentration of innovative resources, and has unparalleled advantages in human resources and enterprise scale resources that are unmatched by other regions in my country, providing unique conditions for the development of "high-tech" industries.

2.1.1 Talent advantage: A very important factor to promote the rapid development of "high-tech" is the factor of talents, including the quantity and quality of talents. Up to October 2018, there were 231,394 graduates from universities (including research institutes) in Beijing. Among them, associate degree accounted for $13.05 \%$, undergraduate degree accounted for $52.28 \%$, master degree accounted for $28.37 \%$, doctoral degree accounted for $6.30 \%$. Among the 2018 graduates who were employed, employment in Beijing accounted for $62.49 \%$ and employment outside Beijing accounted for $37.51 \%$. In terms of educational resources, there are altogether 89 universities and colleges in Beijing, 8 of which are in the "985 Project" and 26 in the "211 Project", accounting for $21 \%$ and $25 \%$ of the national universities respectively. In terms of scientific research resources, Beijing had 79 state key labs by 2018, ranking first in China. It is far more than the 32 state key labs in Shanghai, which ranked second. These resource advantages in education and scientific research provide a solid foundation and guarantee for the cultivation of innovative talents in Beijing, and become the unique talent advantage in Beijing to build a "hightech" industrial economic structure.
Table2. DISTRIBUTION OF COLLEGE GRADUATES IN BEIJING

\begin{tabular}{|c|c|c|c|c|c|}
\hline Year & Total & Specialist & Undergraduate & Master & PhD \\
\hline 2014 & 223450 & 34421 & 112701 & 61437 & 14891 \\
\hline 2015 & 231005 & 37205 & 115696 & 63510 & 14594 \\
\hline 2016 & 229002 & 36032 & 118147 & 61599 & 13224 \\
\hline 2017 & 235318 & 34055 & 119087 & 63268 & 13880 \\
\hline 2018 & 231394 & 29525 & 118287 & 64207 & 14252 \\
\hline
\end{tabular}

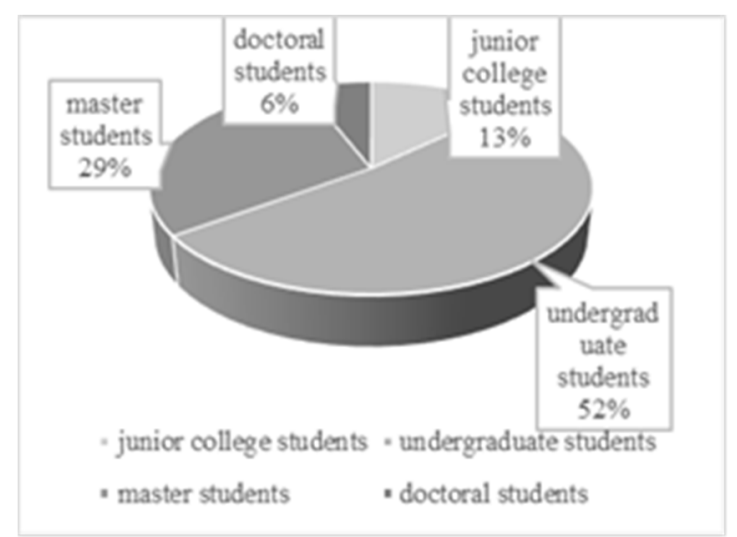

Fig1. Percentage of graduates in Beijing in 2018

2.1.2 Enterprise scale advantage: According to the actual situation of the city's economic development and the existing economic structure, the Beijing Municipal Government proposed to build a "high-tech" industrial economic structure, which is an inevitable trend to transform the economic development model and improve economic benefits [4]. In fact, in addition to domestic companies, most of the world's top 500 companies, such as Hitachi, Toshiba, LG Electronics, Samsung, and Siemens, have their headquarters in Beijing. These companies are engaged in scientific and technological research and development, equipment investment, production and processing in Beijing, which has effectively boosted Beijing's employment level, stimulated market vitality, and helped Beijing build a reasonable "high-tech" industrial structure.

\subsection{Disadvantage}

For Beijing, the development of "high-tech" industrial economy is to cross the river by feeling the stones. In the process of step-by-step exploration and practice, until it develops into an important force serving the capital's economic construction, there will be some problems that cannot be ignored. Only by constantly improving relevant policies and industrial development plans, and improving the ability to adapt to the development of the regional economy, can Beijing Municipal Government provide a steady stream of power support for the capital's economic development [5].

2.2.1 Corporate financing difficulties: To change the default, adjust the template as follows. In recent years, Beijing Municipal Government has put forward many guiding opinions and necessary measures in order to 
promote the development of "high-tech" industries, but there are still many problems that need to be resolved in the financing of "high-tech" enterprises. On the one hand, because "high-tech" companies have the characteristics of high investment, high risk, high output, and high growth [6], in order to avoid risks, the government has introduced relatively conservative financial policies and regulatory measures. To a certain extent, this has restrained financial institutions from providing financial services to "hightech" enterprises, especially small and medium-sized "high-tech" enterprises [7]. On the other hand, in terms of financing, compared with state-owned enterprises, the supporting environment and development resources owned by "high-tech" enterprises are relatively scarce. In addition, the business stability, bargaining power and growth ability of enterprises are all weak, which leads to financing difficulties for "high-tech" enterprises [8]. In the future, the government should build a multi-level, multichannel financing path and operating mechanism based on promoting the development of "high-tech" industries. In addition, the government should introduce powerful financial support measures to improve the financing level of "high-tech" enterprises and lay a solid foundation for innovation-driven development of enterprises.

\subsubsection{Lack of R\&D investment and technological} innovation: Nowadays, on the one hand, many "hightech" companies have insufficient R\&D investment and unicorn companies are not strong. Revolutionary technological innovations have not yet appeared in Beijing's industrial sector [9], and there are no innovative giants like Microsoft and Apple. The R\&D investment intensity of industrial enterprises above designated size in Beijing is only $1.6 \%$, which is lower than the international average. On the other hand, technological innovation does not provide enough support for the development of "hightech" industries, causing enterprises are faced with problems such as not being new in technology, not being cutting-edge in technology, and not making enough innovation in hard technology. At the same time, although Beijing has good conditions and achievements in scientific and technological innovation, the cooperation and integration of innovation chains, industrial chains, functional chain and other aspects is still not sufficient. Only $20 \%$ of Beijing's scientific and technological innovation achievements are transformed in Beijing, and technological innovation capabilities have not really been transformed into "high-tech" industrial competitiveness.

\subsection{Opportunity}

2.3.1 Policy support: When Chinese President Xi Jinping visited Beijing, he proposed Beijing's urban function positioning around the "four centers" of the national political center, cultural center, international exchange center, and scientific and technological innovation center [10]. Among them, the urban function positioning of the "Science and Technology Innovation Center" is an important part of Beijing's reshaping of the urban structure. The repositioning of the city's functions as the "four centers" of the national strategy together with "Beijing-Tianjin-Hebei Integration" and "Xiongan New District" is the biggest opportunity for Beijing to build a "high-tech" industrial economic structure-national strategy Policy support at the level. Subsequently, Beijing carried out a special action of "Resolve, Renovate Promote and Improvement" to accelerate the construction of a "high-tech" industrial structure.

The Beijing Municipal Government will provide powful support for this, including giving full play to the decisive role of the market in allocating resources and giving better play to government functions [11]; promoting the in-depth integration of technological innovation and "high-tech" industries; doing a good job in basic frontier research and key core technology research, cultivating an internationally competitive R\&D and innovation system; realizing the effective and rapid transfer and transformation of scientific and technological achievements; creating a business environment for innovation and development. In addition, Beijing will also study and publish the "Three-year Action Plan for Cultivating and Growing Innovative Enterprises" and the "Beijing Emerging Industry Registration Guidance Catalog", and will form a positive list for the registration of "high-tech" enterprises.

2.3.2 Technological development: After 70 years of development, China has transformed from a country that "can't even make a car" into the only country in the world that has all the industrial categories listed in the United Nations industrial classification. As of June 2018, the number of artificial intelligence companies in China ranked second in the world. Among them, Beijing has 395 artificial intelligence companies, which is the city with the most artificial intelligence companies in the world. In addition, the total number of artificial intelligence papers and the number of highly cited papers in China are both ranked first in the world, and the total number of talents ranks second in the world. It is estimated that in 2020, the scale of China's artificial intelligence market may approach 100 billion yuan. In 2017, the sales revenue of China's integrated circuit design industry reached 207.35 billion yuan, up 26.1 percent year-on-year. Shenzhen, Shanghai, and Beijing are the top three cities in the domestic IC design industry, accounting for more than $60 \%$ of the scale. In the world, the gap between China's IC industry and developed countries is small or at the same level. The progress of science and technology in various fields in Beijing is an important foundation for Beijing to develop "high-tech" industries [12], and it is also a rare opportunity to build a "high-tech" industrial economic structure. In the future, Beijing should rely on the existing technological level, increasing investment in research and development, improving the efficiency of transformation of scientific and technological achievements, and jointly providing assistance for the development of "high-tech" industries. 


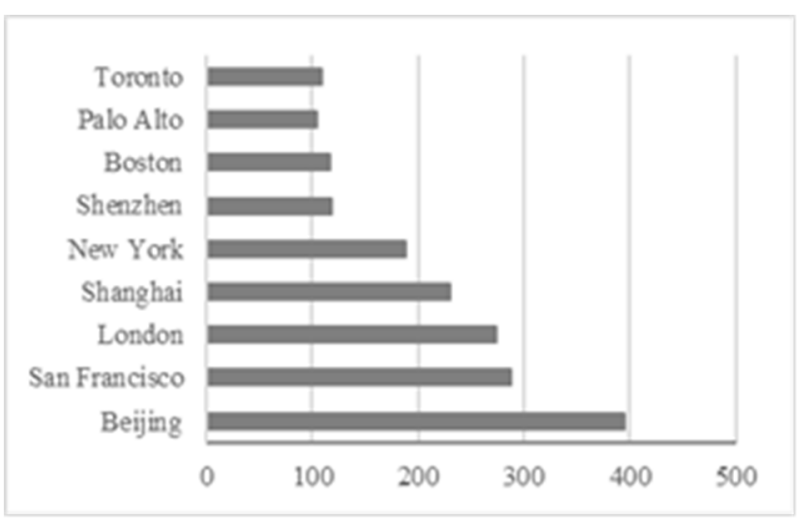

Fig2. Ranking of AI companies by number

\subsection{Challenge}

2.4.1 Competitive pressure increases: Following the introduction of China's first national artificial intelligence development plan "New Generation Artificial Intelligence Development Plan" in 2017, the United States launched the "American Artificial Intelligence Initiative" to mobilize more federal funds and resources for artificial intelligence development from the national strategic level, in order to meet the challenges from global competitors [13]. The development of "high-tech" industries has become an important trend in the economic development of countries around the world. Major countries in the world have raised the development of related "high-tech" industries to a national strategic level. The competitive development of "high-tech" industries in various countries has increased the cost and pressure of competition in China, resulting in a relative shrinkage of the global market scale, reducing the economic benefits of related industries, and hindering the development of "high-tech" related industries in Beijing.

\subsubsection{Difficulties in the transformation and upgrading} of the industry: Compared with traditional industries, "high-tech" industries pay more attention to high intelligence, high added value, and high efficiency, and put forward higher requirements for the guarantee links of related elements. If traditional enterprises want to transform successfully, the initial investment must be increased, including R\&D investment, equipment investment, manpower investment, etc., but it is difficult to obtain a large amount of benefits and recover costs in the short term [14]. At the same time, due to the continuous emergence of new industry models and related "high-tech" industries are constantly penetrating into traditional industries, it is difficult to accurately distinguish industrial boundaries. Therefore, new requirements are placed on the management level of the industry.

\section{Related suggestions}

Beijing has many advantages and opportunities to develop "high-tech" industries, but there are also some problems that need to be resolved urgently. In response to some sharp "problems", I put forward relevant suggestions to better enhance the economic development of "high-tech" industries and the core functions of the capital.

\subsection{Improve the fiscal and tax incentive policies for "high-tech" enterprises}

Fiscal and tax incentive policies can be subdivided into fiscal incentive policies and tax incentive policies. For "high-tech" enterprises with a relatively high proportion of research and development, the government mainly uses financial subsidies and tax incentives to help enterprises and improve their viability. The financial incentive policy refers to the special financial fund provided by the government to improve the survival rate of enterprises. Qualified enterprises apply to the financial department, and the financial department will issue subsidy funds according to the regulations after the approval. The main advantages are highly targeted, controllable and flexible [15]. The preferential tax policy is to provide the corresponding preferential measures for the tax generated by the production and operation activities of enterprises under the current tax system, so thereby enhancing the competitiveness of enterprises.

\subsubsection{Measures to optimize fiscal incentive policies:}

3.1.1.1 Establish a "high-tech" special department to enhance financial vitality: The establishment of special departments for "high-tech" enterprises is conducive to improving the implementation efficiency of fiscal policies, streamlining the fund release process, and enhancing the flexibility of allocated funds. At the same time, clear and detailed relevant documents are formulated, including a series of related documents such as the identification of "high-tech" enterprises, the use objectives and principles of financial incentive funds [16].

3.1.1.2 Diversification of fiscal incentives: In the new environment, the growth of enterprises is increasingly inseparable from diversified fiscal incentive policies. For "high-tech" companies, especially small and mediumsized companies, the independent innovation ability are relatively weak, and their product market share is relatively low. At this time, government finance should play its procurement function, openly purchasing some related technologies from universities, R\&D institutions, and R\&D companies to provide to "high-tech" enterprises, expend the sales channels of "high-tech" products, increase the market share of enterprise products, and jointly promote the development of "high-tech" industries.

\subsubsection{Measures to optimize preferential tax policies:}

3.1.2.1 Revise and improve the tax law system: Despite the continuous improvement of China's tax law, the formulation and improvement of the tax law is always relatively backward compared with the rapidly changing market environment, resulting in the inconsistency 
between the implementation of tax policies and the actual situation and affecting the implementation efficiency of the tax law. In order to promote the better and faster development of "high-tech" industries, Beijing Municipal Government must speed up legislation on tax incentives for "high-tech" industries, and increase the authority and regulation of policy implementation.

\subsubsection{Increase the intensity of indirect tax} incentives: Indirect tax incentives are no longer directly targeted at results. Instead, they encourage companies to expand investment in science and technology, reduce corporate risks, and form the preferential mechanism of "policy-guided market, market-guided enterprise" through preferential policies on investment in research and development, worker wages, and fixed asset depreciation [17]. The practice of developed countries has proved that the transformation of indirect tax preference mode is conducive to improving the level of scientific research and development of enterprises, and has a significant role in promoting effect on the growth of enterprises.

\subsection{Improve financing level}

In today's market environment, whether an enterprise can effectively obtain financial resources is an important factor to measure the enterprise healthy development. The same is true for "high-tech" companies. If an enterprise can quickly obtain financial support, then the enterprise will also obtain a healthy and rapid development momentum, laying a solid foundation for innovationdriven development [18].

3.2.1 Expand financing channels: Broadening the direct financing channels for "high-tech" companies can enable companies to quickly obtain financial support. Support "high-tech" companies to become bigger and stronger with the help of capital through initial public offerings, refinancing and other means. Guide "high-tech" companies to make full use of fixed-income innovative tools such as corporate bonds, continuation bond, and asset securitization products. Constantly enrich the forms of financing, broaden the financing channels, so that it can constantly obtain high-quality supplies from the capital market.

\subsubsection{Improve the "high-tech" enterprise innovation} fund system: On the one hand, social capital can be guided to participate in the technological innovation and industrialization of innovative achievements of "hightech" enterprises. Special funds can be set up to combine industrial technological innovation with scientific and technological finance to solve the financing problems of enterprises in the way of scientific and technological finance. On the other hand, social capital should be encouraged to invest in small and medium-sized "hightech" enterprises. Technology microloans, technology guarantees, technology financing lease companies should be established to activate social capital to help the development of "high-tech" enterprises.
3.2.1.2 Use scientific and technological means to solve credit problems: Big data technology is an effective technical means to solve the problem of enterprise credit. It can not only analyze the historical data of an enterprise and monitor the current data in real time, but also predict the future data based on the historical data and track and analyze the production, orders, inventory and other links of an enterprise [19]. Big data mining technology is used to dynamically track and deeply calculate the credit status of "high-tech" enterprises and industrial chain in which they are located and establish new channels of information communication between banks and enterprises. This method not only provides a quantitative basis for the credit status of enterprises, but also provides data support for the bank's post-loan risk control.

\subsection{Promote the optimized layout of "high-tech" industries}

In order to further optimize the business environment and clarify the classification of "high-tech" industries, Beijing issued the "Catalogue of "high-tech" Industries" in 2018, which divided the "high-tech" industries into 10 major industry categories and 197 emerging sub-categories, laying a solid foundation for the industrial layout.

A good industrial layout can bring many benefits to economic development, such as gathering technological innovation resources, forming a technological innovation network, reducing production costs, saving transaction costs, etc. Finally, the regional brand of each park will be created to enhance regional competitiveness. In order to make better use of the advantages of industrial layout, there are currently three mainstream industrial agglomeration modes: market-oriented industry cluster model; government-supported industrial agglomeration mode; planned industry cluster model. Beijing's "hightech" industrial layout should coordinate the three types of industrial agglomeration modes, combine them with each other, and give play to the advantages of each park, focus on researching the positioning of "high-tech" industries in Beijing's parks and clarify key areas, optimize the layout of the innovation chain and industrial chain, thereby promoting the quality of economic development.

\subsection{Double-chain integration promotes the development of "high-tech" industries}

Double-chain integration refers to the integration of the innovation chain and the industrial chain. There are two development models for the integration of the innovation chain and the industrial chain: one is that the innovation chain promotes the integration of the industrial chain, and technological innovation drives industrial development and further enhances each other; the other is that the industrial chain drives the integration of the innovation chain, and the industry develops to a certain extent by adding technology innovation to achieve mutual integration [20]. Technological innovation is the core of comprehensive innovation. Combining scientific and 
technological means with traditional industries to enhance the technological content of Beijing's traditional industries through double-chain integration. It can solve the problems such as slow technological progress, waste of resources, and development bottlenecks, in order to accelerate the transformation, upgrading and structural adjustment of traditional industries. At the same time, Beijing can take advantage of the development of Beijing's top 10 "high-tech" industries, such as energy conservation, environmental protection, medicine and health, artificial intelligence, and integrated circuits, to promote technological innovation in traditional industries, increase the technological content of products, and increase the added value of industries. The effective integration of the two chains can not only efficiently allocate a series of innovative resources to the research and development links in the key areas of the "high-tech" industry, but also improve the ability of industrial enterprises to absorb and retransform new knowledge and new technologies, and continuously improve the independent research and development ability of the "high-tech" industry.

\section{4 summary}

China's economy has shifted from a stage of rapid growth to a stage of high-quality development, and the development of "high-tech" industries is the mainstream content in the conversion process. The development of this industry has an important guiding and supporting role for the overall economic and social long-term development. Based on the actual development of Beijing's industry, this article analyzes the talent advantages, enterprise scale advantages, technological advantages, and policy advantages of Beijing's development of "high-tech" industries. On the other hand, it also deeply analyzes the financing issues, R\&D issues, competition issues and transformation issues of developing the industry. In order to better promote the development of "high-tech" industries, I put forward suggestions from four aspects to promote the development of Beijing's " high-tech " industries: improving fiscal and tax incentive policies, improving financing methods, optimizing industrial layout, and promoting dual-chain integration. In the future, Beijing should closely focus on the strategic positioning of the capital city, vigorously optimize and adjust the industrial structure, and build a new engine of development with "high-tech" industries as the traction to provide important support for the capital to maintain highquality development.

\section{Acknowledgement}

Supported by Beijing Science and Technology Project

\section{References}

1. Xu Qiang, Ding Shuai, An Jing-wen. Research on the Export Competitiveness of "High-tech" Industries in Zhongguancun Demonstration Zone_-Based on the Complexity of Export Technology[J]. Modern Management Science, 2017(09):27-29.

2. Deng Li-zhu. A Brief analysis on the construction of High-tech industry system in Beijing[J]. QIANXIAN, 2019(03):60-62

3. Xia Tian, Sun Jiu-wen. Consideration and Discussion on Extracting Beijing, s Non-Capital Functions under the Neo-Urbanism [J].Social Science of Beijing, 2017(07):69-78.

4. Li Guo-ping and Zhang Jie-fei. Research on the Transformation Characteristic and Driving Mechanism of Chinese Capital Economy and the Countermeasures on That $[\mathrm{J}]$. China Business and Market,2015,29(08):40-46.

5. $\mathrm{Hu}$ Nai-wu, Tian Zi-fang. The Basic Characteristics and Prospect of China's Economic Growth under the New Normal[J]. Economic Review, 2015(08):1-6.

6. Li Yun-chi, Hu Yu-qing, Li Chang-ping. Some Thoughts on the Financing of Small and Mediumsized Enterprises in Beijing $[\mathrm{J}]$. Expanding Horizons, 2011(04):29-30+56.

7. LV Jinsong. On Financing Constraints of Small and Medium Enterprises[J]. Journal of Financial Research, 2015(11):115-123.

8. Sun Xiaohua; Wang Yun;Xu Ran. Financial development, financing restriction ease and firm $\mathrm{R} \& \mathrm{D}$ investments [J]. Science Research Management, 2015,36(05):47-54.

9. Liu Xiao-yi; Liang Da-peng. Current Situation, Problems and Countermeasures of Innovation Development of State-owned Enterprises in Beijing[J]. Expanding Horizons,2019(03):102-107.

10. Gu Guo-da. Research on the Innovative Work of China's Industrial Transformation and Upgrading under the Digital Economy -- A Review of the New Book "Research on China's Industrial Transformation and Upgrading Under the Digital Economy"[J]. International Economic Cooperation,2019(03):156158.

11. Hong Yin-xing. Theoretical Study of Allowing the Market to Play a Decisive Role in Allocating Resources and Improving the Government's Role[J]. Economic Theory and Business Management, 2014(10):5-13.

12. Zhu Xiangyu, Yan Haili. The Current Development Situation and Comparative Research of Beijing Science Technology Service Industry [J]. Science and Technology Management Research,2017,37(23):105118.

13. Zhang Xin-xin, Liu Hua-dong. Publishing + Artificial Intelligence: New Model and Form of Publishing in the Future-From the Perspective of "New Generation Artificial Intelligence Development Plan' $[\mathrm{J}]$. Science Technology and Publication, 2017(12):38-43.

14. Wang Weicai;Wu Qi. Research on the Measurement and Promotion Strategy of Transformation of Chinese Traditional Manufacturing Enterprises Driven by 
Service-Oriented Manufacturing:Taking the Iron and Steel Enterprises as an Example [J]. Social Sciences in Nanjing,2019(04): 18-24+43.

15. Hu Wen-long. The Current Main Problems and Countermeasures of Tax Preferential Policies to Encourage Innovation in China [J]. China Business and Market,2017,31(09):100-108.

16. Shao Chuan-lin, SHAO Shu-jing. An Evaluation about the Incentive Effect of Government Financial Subsidies on Innovative Performance of Enterprises [J]. Journal of $\mathrm{Xi}^{\prime}$ an Institute of Finance \& Economics,2015,28(06):5-11.

17. Huang Hui-dan, Wu Song-bin. How Big Is the R\&D Tax Incentive Effect? - Investigation Based on Tax Rate and Tax-Based Credits[J]. Forum on Science and Technology in China,2019(09):34-39.

18. Hua Ai-mei. Discussion on Independent Innovation and Financing Support for Small and Medium-sized Technology-based Enterprises[J]. Technoeconomics \& Management Research, 2008(01):28-29.

19. Chen Ying. Research on the Construction of Enterprise Credit System under big Data Technology - Taking the construction of enterprise Credit big data platform as an example[J]. Contemporary Economics, 2015(23):14-17.

20. Zhu Rui-bo. Study on Double-chain Integration Strategy of High-tech Industry Development in Shanghai $[\mathrm{J}]$. Shanghai Economic Review,2010(07):94-106. 